\title{
An empirical assessment of the effects of the Japan-Philippine Economic Partnership Agreement (JPEPA) on Philippine exports to Japan: a gravity model approach
}

\author{
Al Faithrich C. Navarrete ${ }^{1,2,3^{*}}$ (1) and Virgillio M. Tatlonghari ${ }^{1}$
}

${ }^{*}$ Correspondence:

acnavarrete@ust.edu.ph

${ }^{1}$ The Graduate School, University of Santo Tomas, Manila, Philippines Full list of author information is available at the end of the article

\begin{abstract}
The Japan-Philippines Economic Partnership Agreement transcends conventional bilateral trade agreements as it contains measures to facilitate cooperation and investment in capital, technology, and people. Liberalization aims to facilitate trade between the two economies by eliminating restrictions. A modified gravity model was utilized using weighted average tariff rates imposed by Japan to Philippine exports to estimate the impact to Philippine export to Japan. Based on the findings, declining average tariff rate of Japan increases imports from the Philippines after one (1) period lag. The Japan-ASEAN economic partnership agreement also has a significant impact on the trade flow between Japan and Philippines.
\end{abstract}

Keywords: Bilateral trade agreement, Trade, Gravity model, Tariff reduction

\section{Background}

Japan has been one of the largest trading partners of the Philippines. In February 2004, the Philippines and Japan started negotiations for a bilateral trade agreement known as the Japan-Philippines Economic Partnership Agreement (JPEPA). Under the agreement which was eventually signed in September 2006, 66\% of the current 5968 tariff lines were immediately eliminated and the remaining $32 \%$ were to progressively reduce. The agreement also included the accord for national treatment of investors as well as the most-favored-nation.

The elimination of tariffs was expected to increase trade between the two countries. The national treatment accord gave Japanese investors the same treatment as Filipino investors in the Philippines and vice versa in Japan. These two (2) main pillars together with other provisions were expected to enhance mutually beneficial economic activities between the two countries.

It has been more than 10 years since the signing of the agreement and no empirical analysis has been done to assess the overall performance of the economic partnership. Based on the data from UN COMTRADE statistics, exports of the Philippines to Japan increased by $24 \%$ in 2010, 2 years after implementation of the agreement.

(c) The Author(s) 2018. This article is distributed under the terms of the Creative Commons Attribution 4.0 International License (http://creativecommons.org/licenses/by/4.0/), which permits unrestricted use, distribution, and reproduction in any medium, provided you give appropriate credit to the original author(s) and the source, provide a link to the Creative Commons license, and indicate if changes were made. 
While many studies analyze the impact of trade on bilateral agreements using the standard Gravity model, many of its limitations can still be improved. Also, the elimination of different tariff lines with varying reduction cannot be taken into account in the standard Gravity model.

Since the agreement has several economic and non-economic components, this paper will limit itself only on the economic impact to trade volume between the two countries before and after the implementation of JPEPA. Therefore, socio-cultural dimensions of the Agreement will not be dealt with. The impact of other free trade agreements entered into by Japan and the Philippines with other countries will be outside the ambit of this paper and will instead focus only on their bilateral trade.

An important economic dimension of the agreement which this paper hopes to unravel would be the possible increase, if any, in foreign direct investments of Japan to the Philippines as well as in the improvement of the Philippine trade balance with Japan.

\section{Literature review}

Regional trade agreement (RTA) is an agreement between two or more countries wherein trade is facilitated through elimination of barriers to trade between the countries involved (Kahouli and Maktouf 2015; Zhou 2015; Bilas and Franc 2016; Hayakawa et al. 2016). Free trade agreements remove restrictions to trade goods as well as open service and investment markets between agreeing parties (Zhang et al. 2007). Almost all countries now are participating as partners in at least one RTA (Zhou 2015).

Trade liberalization's primary goal is to foster faster economic growth (Liu 2016). Although free trade has been viewed as an instrument for development, it must also be considered that natural competition aspect may hinder development for developing countries (Stoneman and Thompson 2007).

According to Zhou (2015), RTAs need institutional structures to facilitate trade and create positive impact to the economy (Arvis and Shepherd 2013). These institutional structures include guidance for economic exchanges, reduce uncertainties, smooth transaction process, and mitigate negative externalities of the market. Countries are using RTAs as a strategy for global trade expansion, hence it is expected that its popularity will continue to grow (Zhou 2015). The effectiveness of RTAs may be dependent on its design, content, and length of time in effect (Grant and Lambert 2008), but its main purpose should be to create positive significant welfare effect both to partner and nonmember countries (Park and Park 2011). An integration that focuses on trade discrimination alone may not be sufficient to create significant effects (Park and Park 2016). As RTAs increase trade in member countries, called (trade creation) and avert trade to nonmembers (trade diversion) (Girma et al. 2008; Freund 2010; Suvannaphakdy and Toyoda 2014; Kahouli and Maktouf 2015), its negative impact to non-members should be minimized (Park and Park 2011). Trade diversion goes beyond not favoring non-member countries; it is actually a welfare loss since it diverts trade away from most efficient global producer (Freund 2010).

Since 1990 intra-regional trade flows in East Asia have gradually increased through free trade agreements (FTAs). This is also referred to as the second wave of regionalism (see Urata 2004; Yoshimatsu 2005; Ali and Caldentey 2007; Liu 2007; Bui 2008; Park and 
Park 2011; Jalles 2012; Reyes et al. 2014; Suvannaphakdy and Toyoda 2014; Kahouli and Maktouf 2015).

Based on the study of Suvannaphakdy and Toyoda (2014), bilateral trade flow had positive effect on overall GDP and that the expansion of ASEAN into ASEAN +3 and ASEAN +6 promoted the exports of the member countries thru the elimination of tariffs. Free trade agreement (FTA) enabled Vietnam and Mexico to have greater access to markets and attract foreign direct investments (FDIs) and which was likely to improve economic welfare (Bui 2008). Free trade agreements have facilitated positive effects such as technological progress and rapid economic growth (Urata 2004).

The creation of Regional Trade Agreement (RTA) significantly increases trade flow (Vicard 2009) and that RTAs' effects are strengthened through time (Reyes et al. 2014). Being a member of a Free Trade Agreement (FTA) can also increase agricultural trade flow (Hndi et al. 2016). Usually for developing countries, higher protection is given to the agricultural sector (Grant and Lambert 2008).

However, some studies suggest that regional trade agreements do not affect the growth of a nation (Jalles 2012) and that its effects are unclear (Jalles 2012; Reyes et al. 2014). Further, it may also have both positive and negative effect on multilateral free trade (Bilas and Franc 2016).

Due to the slow progress of the multilateralism through the General Agreement on Tariffs and Trade (GATTS) of the World Trade Organization (WTO) (Ali and Caldentey 2007; Zhang et al. 2007; Yoshimatsu and Ziltener 2010), Japan has shifted its trade liberalization priorities to regional and bilateral agreements (Yoshimatsu and Ziltener 2010). Initially, Japan made trade agreements with developing countries in Southeast Asia and Latin America. The first Free Trade Agreement (FTA) of Japan is with Singapore in 2000, followed with Mexico and Malaysia (Yoshimatsu and Ziltener 2010).

Further anticipation of the impact of China in the world market, Japan entered into a Free Trade Agreement with Malaysia (Rahman et al. 2008a, b). The Free Trade Agreement between Japan and Malaysia created a positive significant impact in the bilateral trade between the two countries (Rahman et al. 2008a).

The Gravity Model is widely used to measure the effects of Regional Trade Agreements (RTA) to trade flow (Grant and Lambert 2008; Liu 2007; Freund 2010; Peci et al. 2010; Ghosh 2011; Silva and Nelson 2012; Gomez-Herrera 2013; Sen et al. 2013; Drzewoszewska 2014; Oncel and Tekce 2014; Sanora 2014; Khosla 2015; Kulkarni et al. 2015; Mohmand et al. 2015; Eita 2016; Madah and Nagheli 2016; Park and Park 2016; Quammer and Baba 2016). Gravity model assesses the trade flow of a country and is very important in determining potential of exports or imports of a country (Arvis and Shepherd 2013, Eita 2016). It assumes that the trade between countries are proportionate to the income of the countries measured in GDP and indirectly proportional to the distance or transportation cost between the trading partners (Tansey and Hanson 2011). Suvannaphakdy and Toyoda (2014) used import tariff as an additional variable in the gravity model.

Suvannaphakdy and Toyoda (2014) empirically tested the impact of tariff rates and other determinants to trade flows within ASEAN, ASEAN + 3, and ASEAN + 6 using the gravity model and fixed-effect model. Hndi et al. (2016) measured the impact of Free Trade Agreement (FTA) to agricultural trade flow in North African countries using the 
gravity model and a panel data set. Silva and Nelson (2012) developed an asymmetric gravity model between developed and developing trade partners using a log-linear Taylor-series expansion.

Despite the econometric limitations of the gravity model, it has become a popular method of analysis of bilateral trade (Nastic 2013). The gravity model often faces problems such as heteroskedasticity in trade and zero flows of trade (Burger et al. 2009; Gomez-Herrera 2013; Papalia and Bertarelli 2015).

There are two (2) methods that can be used to measure the impact of bilateral trade barrier, the gravity model and trade intensity index (Chen and Li 2014). The integration of these two methods that were used by Chen and Li (2014) is called the gravity model adjusted intensity (GMATI). It covers the short run trade barriers such as tariffs, non tariff barriers, and anti dumping duties, as well as the long run in the global trade context, such as distance, economic structures, and the like (Chen and Li 2014).

Most of the studies which analyzed the effects of bilateral trade use panel data regressions to find empirical results (see Arvis and Shepherd 2013; Fratianni and Oh 2009; Stack 2009; Vicard 2009; Sohn and Lee 2010; Garcia et al. 2013); Naanwaab and Diarrassouba 2013; Drzewoszewska 2014; Ravishankar and Stack 2014; Sanora 2014; Gervais 2015; Kunroo and Azad 2015; Bujang 2016; Cipkute 2016; Eita 2016; Iqbal 2016; Liu 2016; Park and Park 2016).

Reyes et al. (2014) utilized different gravity models. The first one considered the economic size of the countries, distance, and other controlling variables such as language. Another set of gravity models included multilateral price variables. Sherif (2013) used pooled cross sectional (PCS) method in the standard gravity model to assess the bilateral trade of United Arab Emirates with Bahrain and Qatar as a group. Boxell (2015) used the $\mathrm{k}$-fold cross-validation in examining the gravity model; this method provides more robust model and prevents over-fitting the model.

Studies that used gravity model to measure the impact of a Regional Trade Agreement usually encounter econometric problems such as the endogeneity of RTA variables, the explanatory variable, and the treatment of zero trade values (Burger et al. 2009; Tansey and Hanson 2011; Urata and Okabe 2014). Using aggregated data also miscalculates the real impact of the RTA since the tariff elimination differs in a product level (Urata and Okabe 2014).

The use of aggregate data in the analysis of the effects of Regional Trade Agreements to trade flows results to inconsistent findings (Grant and Lambert 2008). The Poison pseudo-maximum likelihood (PPML) model addresses the inaccuracy of estimated due to the zero trade values as well as perform a product-level analysis (Arvis and Shepherd 2013; Urata and Okabe 2014; Luqman et al. 2015; Proenca et al. 2015; Egger and Staub 2016; Park and Park 2016). Clausing (2001) also used disaggregated data, on the commodity level, to analyze the impact of RTA in Canada-United States Free Trade Agreement (CUSFTA). The agreement had a statistically significant effect on trade flow between Canada and the United States (Clausing 2001).

The Poison Quasi-Maximum Likelihood (QML) is the only method that overcomes the common trade flow problem in a gravity model that actual trade flow is less than the predicted trade flow, this is known as the adding up problem (Arvis and Shepherd 2013). Luqman et al. (2015) used a fully modified ordinary least squares (FMOLS), canonical 
cointegrating regression (CCR), and Poison pseudo maximum-likelihood (PMML) models to deal with this issue.

Hayakawa et al. (2016) used disaggregated tariff line-level trade data and used the standard gravity equation in order to isolate effects of different tariff reduction schedule. Trade Intensity Index (TII) measures barrier to trade based on the relative trade of a country to its partner and to the rest of the world (Chen and Li 2014); Jarreau (2015) used panel data to estimate elasticity of trade using tariff protection on a sector-level.

A structural type of gravity model may be derived using a multi-sector Armington model that covers agriculture, mining, and manufacturing (Jarreau 2015).

Bilateral trade agreement is perceived to bring about positive impact to the trading countries by increasing trade and economic activity in the two countries. It has been established that the success of bilateral trade is not only reliant on the level of tariff elimination between the partner countries but with other factors as well as other parts of the agreement that facilitates not only trade but also investment and deeper cooperation between the countries. The effects of a trade agreement differ depending on the auxiliary components of the agreement and the current conditions of the participating countries.

The Gravity Model, although with limitations, is so far, the most commonly used model in assessing the impacts of a trade agreement. Several augmentations and modifications of the gravity model have been done already including the disaggregation of trade volumes. Other methods in econometrics are also combined with this in order to address its limitations and come up with a more statistically sound assessment of the agreement.

\section{Theoretical framework}

Benedictis and Taglioni (2011a, b) cited in their study how the Gravity Model of trade evolved. According to them, Jan Tinbergen, the first Nobel prize winner in Economics, in his Ph.D. thesis in 1929 entitled Minimum Problems in Physics and Economics borrowed Newton's law of gravitation in measuring intensity of bilateral trade flows. Briefly, the law determines gravitational intensity between two (2) celestial bodies as directly proportional to the product of their masses and inversely proportional to their distance. He developed his first econometric model of the gravity equation as applied to international trade in 1969 as Tinbergen's interest shifted from physics to economics. Since the 1960s, the model has been used to analyze its impact on international trade.

Applied to bilateral or multilateral trade, the mass of a country is usually represented by its economic size measured in terms of its aggregate output or gross domestic product (GDP) while its geographic distance measures the impediment or resistance to trade with its trading partner. The standard gravity equation or model of trade is a non-linear model which consists of three (3) explanatory variables as captured in the following equation (Eita 2016; Benedictis and Taglioni 2011a, b):

$$
X_{i j}=\frac{G\left(M_{i} M_{j}\right)}{D}
$$

where $X_{i j}$ represents bilateral commodity trade flows, $G$ is a constant, $M_{i}$ is the economic size of country $i, M_{i}$ is the economic size of country $j$, and $D$ stands for geographic distance between the two (2) countries. However, the model is flexible enough to allow for 
its augmentation by non-economic factors such as population, language, culture and policy variables as follows:

$$
X_{i j}=\frac{B\left[Y_{i}^{\beta 1} \cdot Y_{j}^{\beta 2} \cdot N_{i}^{\beta 3} \cdot N_{j}^{\beta 4} \cdot A^{\beta 5}\right]}{D}
$$

Here the added superscripted variables, $N^{\beta 3}$ and $N^{\beta 4}$ are population levels of the two (2) countries, and $A^{\beta 5}$ is a policy variable which could be implemented or introduced by a country. $B$ is a constant of proportionality equal to $G$ in (1). Logarithmically this is its equivalent to the following expression

$$
\ln X_{i j}=\beta_{0}+\beta_{1} \ln Y_{i}+\beta_{2} \ln Y_{j}+\beta_{3} \ln N_{i}+\beta_{4} \ln N_{j}+\beta_{5} \ln D_{i j}+\beta_{6} \ln A_{i j}
$$

where $X_{i j}$ represents the export and import of goods from country $i$ to country $j, Y_{i}$ is the GDP of country $i, Y_{j}$ is the GDP of country $j, N_{i}$ and $N_{j}$ are the population levels of the exporting and importing country, $D_{i j}$ is the distance between the two countries, and $A_{i j}$ is any other factor that my influence or restrict trade between the two countries.

\subsection{Research questions}

From an empirical standpoint, this study aims to provide answers to the following specific concerns:

(a) Historically, what has been the impact of the economic partnership agreement between the Philippines and Japan, officially known as Japan Philippine Economic Partnership Agreement (JPEPA), to bilateral trade flows between the two (2) countries;

(b) Do the relative sizes of the economies of Japan and the Philippines as measured by their respective real gross domestic products (GDP) influenced trade flows in a significant manner as far as the Philippines is concerned?

(c) Does the change in tariff structure arising from the Agreement enhanced trade volume between the two (2) countries relative to what it was before?

(d) Are transportation or shipping costs any different before and after the implementation of the trade agreement between the Philippines and Japan?

(e) Is the hypothesized relationship on trade flows between Japan and the Philippines a stable and predictable one?

(f) Is there a long-term or equilibrium relationship between trade flows and the predictor variables identified in the preceding questions?

(g) Can JPEPA serve as a model or template for future trade agreements that the Philippines may enter into with other developed countries?

While most of the studies that have been reviewed so far in relation to this paper used the standard gravity model as well as the Poisson pseudo maximum-likelihood model, very few have used disaggregated data on trade volume relative to the corresponding tariff reduction created by the bilateral trade agreement. 
This paper aims to come up with a predictive model which uses, among others, a weighted average of the disaggregated data on the tariff structure covered in the trade agreement and how its changes over time that impact on bilateral trade flows. This aspect of the research plus its potential to systematically fill the gap or lack of known policy evaluation regarding the impact of JPEPA to the Philippine economy could be the major contribution of this study.

\subsection{Research paradigm}

To accomplish the research objectives of this paper, the following conceptual framework serves as a blueprint or guide in empirically estimating a gravity model of trade relationships between the Philippines and Japan.

The diagram assumes that all the explanatory factors are exogenous and exert therefore a unidirectional flow towards the direction of trade volume between Japan and the Philippines.

Symbolically, the functional relationship implied by Fig. 1 is expressed mathematically as follows:

$$
X_{i j}=B f\left(\begin{array}{cccc}
Y_{j} & Y_{p} & \text { AT } & D \\
(+) & (+) & (-) & (-)
\end{array}\right)
$$

where the algebraic signs in small parentheses below each explanatory variable indicate the direction of its effect on trade flows.

An increase in the relative sizes of the two (2) economies' GDP is expected to lead to an increase in exports or trade volume, hence the positive signs on both. Intuitively, if Japan's GDP expands, ceteris paribus, it can raise its imports from the Philippines which serves as the latter's exports to the former. This creates a series of feedback effects that reinforce the two countries' GDP.

On the other hand, a reduction in average tariff rate which is expected out of the Agreement would be tantamount to increasing the proximity of the two countries and encourage more trade and redound therefore to the benefit of the partners to the trade agreement.

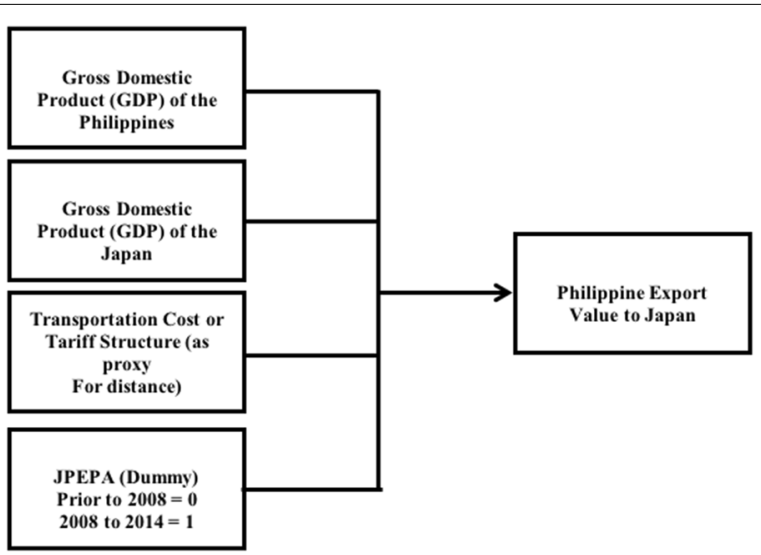

Fig. 1 The gravity model of Philippines-Japan trade relationship 
The implementation of a trade agreement is expected to enhance trade relationship as it dismantles unnecessary tariff and non-tariff barriers and smooth out trade impediments. It should therefore exert a positive effect on trade.

\section{Research hypotheses}

The following research hypotheses would be tested in this study:

Ho 1 Bilateral trade flows between Japan and the Philippines are not significantly affected by the relative sizes of the two (2) countries' aggregate output as measured by their real Gross Domestic Product, the implementation of the JPEPA, and tariff structure of imports and exports between the two (2) countries, when taken individually or collectively;

Ho 2 Changes in the tariff structure of commodity trade between Japan and the Philippines do not exert any significant effect on trade flows between the two (2) countries;

Ho 3 The implementation of the trade agreement JPEPA does not exert any significant effect on trade flows between the Philippines and Japan'

Ho 4 There is no long-run or equilibrium relationship between trade flows and the relative sizes of Japan and Philippines' GDP, tariff structure, and implementation of JPEPA.

\subsection{Research design}

The research design of this study follows a descriptive-causal approach. The descriptive aspect will dwell on a historical narrative of the different measurable factors that explain trade between the Philippines and Japan. This will require supporting tables or charts on the pertinent variables conditioning trade between the two (2) countries as well as appropriate descriptive statistics. Qualitative analysis will be provided in the process.

The causal aspect of the study will be in terms of estimating an empirical model of the hypothesized relationships between trade volume and the suspected conditioning variables and their effects and magnitudes over a specified period of time which encompasses or straddles the implementation of the Japan-Philippine Economic Partnership Agreement (JPEPA). An important component of this aspect is the determination of how significant the hypothesized effects of the agreement are and whether they are consistent or not with the gravity model.

\subsection{Data and sources}

Historical data on Philippine exports to Japan would be obtained from the Philippine Statistics Authority (PSA) through Trade Statistics for International Business Development. Data on real gross domestic product (GDP) of the Philippines and Japan would be sourced online from the Asian Development Bank (ADB) and the International Monetary Fund (IMF).

Since the geographic distance between the Philippines and Japan is constant, a proxy for distance which allows variability over time would be the weighted average tariff rate (AT). 
The tariff rate will be the weighted average tariff rates by value of the goods traded between Philippines and Japan. The study will cover all tariff lines based on the category of tariff eliminations which resulted from the JPEPA negotiations. The formula used for the derivation of the weighted average tariff rate (AT) is as follows:

$$
\mathrm{AT}=\left[\mathrm{TR}_{i} V_{i} \cdots+\mathrm{TR}_{\text {in }} * V_{\text {in }}\right] / \text { Total Value of Trade }
$$

Data on the specified tariff per type of products traded will be gathered from the Trade Analysis Information System (TRAINS) of the United Nations Conference on Trade and Development (UNCTAD).

This study covers the period from the first quarter of 2001 to the fourth quarter of 2014, a total of 56 observations.

\subsection{Research methods}

A multiple regression analysis using ordinary least squares (OLS) procedure will be applied on the empirical models discussed in the following sections.

While the hypothesized economic models are non-linear in form, transformation of the models in logarithms will make them intrinsically linear in their parameters rendering them suitable for estimation by OLS.

\subsubsection{Economic models}

In logarithmic form of the regression model used in the study is as follow:

$$
\ln \mathrm{TV}_{t}=\beta_{0}+\beta_{1} \ln Y_{P t}+\beta_{2} \ln Y_{J t}+\beta_{3} \mathrm{AT}_{t}+\beta_{4} D_{i}+u_{i}
$$

Equation (6) is the gravity model of trade applied to the Philippines and Japan, where $\mathrm{TV}_{t}$ is the value of exports and imports of the Philippines to Japan, $Y_{p t}$ is the Philippines real GDP, $Y_{j t}$ is Japan's real GDP, $\mathrm{AT}_{t}$ is the Philippines weighted average tariff rate as proxy for distance, and $\mathrm{D}$ is a dummy variable for the implementation of JPEPA. $U_{t}$ is a stochastic error term. This model will also estimate the impact of JPEPA on trade flows between Japan and the Philippines.

The model will be estimated by multiple regression analysis using ordinary least squares (OLS) procedure. Parameter estimates and diagnostics will be facilitated using

\begin{tabular}{|c|c|c|}
\hline Diagnostic test & Procedure & Results \\
\hline Test for stationarity/unit root test & Augmented Dickey Fuller & Variables are stationary at second difference \\
\hline Autocorrelation in the residuals & Breusch-Godfrey LM test & $\begin{array}{l}\text { Low; possibility of serial autocorrelation, } \\
\text { corrected using HAC procedure using } \\
\text { Newey-West }\end{array}$ \\
\hline Normality test of residuals & Jarquc-Bera & Normally distributed \\
\hline Test for multicollinearity of variables & Variance inflation factor & $\begin{array}{l}\text { There is no multicollinearity among the } \\
\text { variables }\end{array}$ \\
\hline Test of structural stability & Chow breakpoint test & No structural changes in the variable \\
\hline Test f or misspecification & Ramsey RESET & No misspecification error \\
\hline Test of cointegration & $\begin{array}{l}\text { Johansen cointegration/ } \\
\text { Dickey Pantula principle }\end{array}$ & $\begin{array}{l}\text { There is a long-run relationship between the } \\
\text { variables }\end{array}$ \\
\hline Test of endogeneity & Hausmann specification test & \\
\hline
\end{tabular}
econometric software such as E-Views and Stata. 


\subsection{Statistical treatment of data}

The following statistical procedures would be employed to generate parameter estimates and diagnostic tests of the empirical models.

\subsubsection{Test of stationarity of variables}

Before any regression analysis on time series variables can be applied, each univariate series on real GDP of the Philippines, real GDP of Japan, and average tariff structure (AT) would be subjected to unit root testing or stationarity test using the Augmented Dickey Fuller (ADF) procedure. The test equation is summarized as follows:

$$
\Delta y_{t}=\alpha+\beta t+\gamma y_{t-1}+\sigma_{1} \Delta y_{t-1}+\cdots \sigma_{p} \Delta y_{t-p}+v_{t}
$$

where $\Delta y_{t}=$ first difference of the variable of interest, $\alpha=$ intercept; $B=$ coefficient on time trend; $\gamma=$ coefficient of lagged dependent variable; $\sigma=$ coefficient of lagged difference term of the univariate series to correct for the presence of autoregressive terms.

The statistical significance of the coefficient, $\gamma$, will be tested using McKinnon critical values at $1 \%, 5 \%$, and $10 \%$ levels of significance. If the computed ADF statistic is more negative than McKinnon critical values, the univariate series is said to be stationary. Otherwise, it has a unit root or is non-stationary. This procedure will be applied at the level series, first differenced series, and, if necessary, second differenced series, on all variables of the model.

The logic behind this procedure is to avoid spurious regression results when dealing with non-stationary variables.

\subsubsection{Test of autocorrelation in the residuals}

Detecting and correcting for the presence of serial correlations in time series regression models are standard econometric procedures. They are necessary to avoid understating standard errors and unduly inflate tests of significance of parameters and avoid specification errors too.

In this paper, the Breusch-Godfrey LM test, a more general test of autocorrelation, in tandem with the popular Durbin-Watson test, would be applied. The BG formula is applied by first generating regression residuals from the model and regressing the residuals on the original regressors and lagged values of the residuals in the following manner, assuming a three-variable model and 2 lags with a reasonably large sample size (Danao 2013):

$$
U_{t}=\alpha_{0}+\alpha_{1} X_{1}+\alpha_{2} X_{2}+\alpha_{3} U_{t-1}+\alpha_{4} U_{t-2}+\cdots \alpha_{k} U_{t-p}+\epsilon_{t}
$$

The coefficient of determination $R^{2}$ of this auxiliary regression, multiplied by degrees of freedom $(n-p)$, where $p$ is the number of lagged error terms, approaches a Chi square distribution. Therefore, if the computed Chi square exceeds critical value there is evidence of higher order serial correlation. Determining appropriate lag length could be done by inspecting succeeding values of AIC (Akaike Information Criterion) of Schwarz. Bayesian Criterion (SBC). 


\subsubsection{Normality test of residuals}

In linear regression models, normality of the error terms is a desirable property because If this assumption is violated, tests of significance and confidence intervals are no longer valid (Gujarati and Porter 2009). A popular test to implement this is the Jarque-Bera (JB) test as follows:

$$
\mathrm{JB}=n\left[\frac{S^{2}}{6}+\frac{(K-3)^{2}}{24}\right]
$$

where $n$, sample size; $S$, skewness coefficient, and $K$, kurtosis coefficient;

If the computed JB statistic is greater than the critical Chi square value at a given level of significance, then the null hypothesis of normally distributed errors should be rejected. Otherwise, the null hypothesis is accepted or cannot be rejected.

\subsubsection{Test for multicollinearity of variables}

If the explanatory variables in the hypothesized model are highly correlated, it would be extremely difficult to isolate their true individual effects on the regressand. A widely accepted test to determine the extent of multicollinearity in a model is the Variance Inflation Factor (VIF). The test is done by regressing each explanatory variable on all the other explanatory variables and the coefficient of determination, $R^{2}$, obtained.

Then the VIF is computed as follows:

$$
\mathrm{VIF}=1 /\left(1-R_{j}^{2}\right)
$$

If the computed VIF has a value lower than 10, there is no serious multicollinearity problem among the predictors (Gujarati and Porter 2009). This process would be repeated for all the other explanatory variables of the model. There are various remedies suggested if there is evidence of multicollinearity in the model, including respecification of model itself.

\subsubsection{Tests of structural stability of models}

If the parameters of a regression model are likely to change, its results would be unreliable and cannot be used for forecasting or policy formulation. This means a structural change has occurred. To detect if there is indeed a structural change in the relationship between the dependent variable and its predictors (a convenient test is to use the Chow Breakpoint test (Gujarati and Porter 2009), This test uses the F-statistics to accept or reject the null hypothesis of no structural change, viz:

$$
F=\frac{\left(\mathrm{RSS}_{\mathrm{R}}-\mathrm{RSS}_{\mathrm{UR}}\right) / k}{\left(\mathrm{RSS}_{\mathrm{UR}}\right) /\left(n_{1}+n_{2}-2 k\right)}
$$

where: $\mathrm{RSS}_{\mathrm{R}}$, restricted residual sum of squares; $\mathrm{RSS}_{\mathrm{UR}}$, unrestricted residual sum of squares; $N_{1}$, sample of observations before the breakpoint; $N_{2}$, sample of observations 
after the breakpoint; $k,\left(n_{1}+n_{2}-2 \mathrm{k}\right)$, degrees of freedom for numerator and denominator, respectively.

If the computed $\mathrm{F}$ statistic exceeds the critical $\mathrm{F}$ value at a specified level of significance, the null hypothesis of structural stability in the regression parameters is rejected. This means the model is structurally unstable and cannot be used for forecasting or policy analysis. Otherwise, the null hypothesis is accepted.

Alternatively, a recursive least square procedure can be applied by regressing the model initially using a restricted sample. The regression is applied iteratively by adding unit of observation for each trial until the entire sample is exhausted. The forecast errors are computed and cumulated and tested using the CUSUM procedure (Enders 2010) as follows:

$$
\operatorname{CUSUM}_{N}=\sum_{I=n}^{N} e_{i}(1) / \sigma_{e} \quad N=n ; T-1
$$

where $N$ is total number of observations, $\mathrm{n}$ is number of observations for initial regression as basis for estimating forecast errors, e is forecast errors, and $\sigma_{e}$ is the standard error of forecast. The cumulated errors when plotted should be within the band of $\pm 0.948\left[(T-n)^{0.5}+2(N-n)(T-n)^{-0.5}\right]$ at 5 percent level of significance. This means there is no structural break. Otherwise, instability is present which can also be visually detected in the graphical plot.

\subsubsection{Test of misspecification}

A mis-specification test using Ramsey's RESET (regression specification error test) procedure would be employed to check for possible omitted variables, redundant explanatory variables, and incorrect functional form in the model. To implement this test, the structural equations would be estimated first. Then fitted values or estimates of the regressand, raised to the $2^{\text {nd }}$ and $3^{\text {rd }}$ powers or even higher would be included as explanatory variables in the original model. For example, a three-variable regression is estimated as follows:

$$
Y_{t}=\beta_{0}+\beta_{1} X_{i t}+\beta_{2} X_{2 t}+\beta_{3 t} Y^{2}+\beta_{4 t} Y^{3}+v_{t}
$$

The $R^{2}$ of this auxiliary regression when multiplied by total number of observations, $n R^{2}$, follows a Chi square.distribution. Therefore, if the computed Chi square value exceeds the critical Chi square values at specified level of significance, there is evidence of specification error in the model. Alternatively, an F-test in terms of the old and new coefficients of determination $R^{2}$ (see Gujarati and Porter 2009) can be calculated as follows:

$$
F=\frac{\left(R_{\text {new }}^{2}-R_{\text {old }}^{2}\right) / \text { no. of new regressors }}{\left(1-R_{\text {new }}^{2}\right) /(n-\text { no. of parameters in new model })}
$$

This is a form of restricted F-test in the sense that if the fitted values of the regressand are found statistically significant then the original model is mis-specified. Therefore, If the computed F-statistic exceeds critical value at specified level of significance, then the 
null hypothesis of no specification error is rejected. This means a specification error has been committed which will necessitate remedial measure or a complete overhaul of the model. Otherwise, the test cannot be rejected and the model can be treated as correctly specified.

\subsubsection{Test of heteroskedastic residuals}

An important characteristic of a regression model is that the regression residuals, as estimators of the population regression disturbance term, are constant or homoscedastic. If this assumption is violated, parameter estimates would be inefficient and unreliable and could therefore lead to erroneous conclusions about the model (Gujarati 2011).

To test this assumption, the hypothesized model is first estimated and its squared residuals, $U^{2}$, generated. Then the residuals are regressed against the original explanatory variables and their squares (no cross product version), and their cross products (with cross product version) in the following manner, assuming hypothetically two (2) explanatory variables.

$$
\begin{aligned}
& U^{2}=\alpha_{0}+\alpha_{1} X_{1}+\alpha_{2} X_{2}+\alpha_{3} X_{1}^{2}+\alpha_{4} X_{2}^{2}+\alpha_{5} X_{1} X_{2}+\epsilon_{i} \\
& U^{2}=\alpha_{0}+\alpha_{1} X_{1}+\alpha_{2} X_{2}+\alpha_{3} X_{1}^{2}+\alpha_{4} X_{2}^{2}+v_{i}
\end{aligned}
$$

Equation 15 is the crossed term option which also serves as a test of specification error while Eq. 16 is the no crossed term option which is a pure test of heteroskedasticity. Under the null hypothesis of no heteroscedasticity, the sample size, n, when multiplied by the coefficient of determination, $R^{2}$, obtained from the auxiliary regression, asymptotically follows a Chi square distribution with $\mathrm{df}$ equal to the number of regressors, $\mathrm{p}$, excluding the constant term (Gujarati and Porter 2009). That is, $n R^{2} \sim \mathrm{X}_{p}^{2}$. Therefore, if the computed Chi square exceeds critical value at specified level of significance, heteroskedasticity cannot be ruled out. Otherwise, the null is accepted.

If both autocorrelation and heteroskedasticity are evident in the model, a more robust estimation of the parameters could be implemented using the Newey-West procedure (Gujarati and Porter 2009). This procedure corrects the variances and standard errors of the estimated parameters of the model without altering the values of the coefficients of the original model. This is also based on the assumption that the sample size is reasonably large.

For time series models, a variant of test of heteroskedasticity is the White-ARCH procedure which determines if the variance of the regression residuals is autocorrelated and heteroskedastic.

\subsubsection{Test of cointegrating relationships}

In multivariate models using time series variables, the assumption that the variables are stationary no longer holds as they generally exhibit trending behavior. Hence their means and variances are not constant. Therefore regressing a non-stationary variable on other non-stationary variables is invalid unless all the variables have identical unit roots or are cointegrated.

A test of cointegrating relationships for a multivariate model was developed by Johansen and Juselius, more popularly known as the Johansen Cointegration Test. This 
test procedure uses the following test equation in vector error correction (VECM) form (Asteriou and Hall 2007).

$$
\Delta Z_{t}=\Gamma_{1} \Delta Z_{t-1}+\Gamma_{2} \Delta Z_{t-2}+\cdots+\Gamma_{k-1} \Delta Z_{t-k-1}+\Pi \Gamma_{t-1}+u_{t}
$$

where $Z=$ vector of variables of the model, $\Gamma=\left(I-A_{1}-A_{2} \ldots A_{k}\right)$ matrix of short-run coefficients of endogenous variables lagged by several periods and $\Pi=-\left(I-A_{1}-A_{2}-A_{k}\right)$ a matrix of coefficients which can be decomposed into $\Pi=\alpha^{\prime} \beta$ matrix where $\alpha=$ speed of adjustment to disequilibrium, and $\beta$ is the matrix of long run coefficients. Unlike the Engel-Granger which tests for the stationarity of regression residuals to detect cointegration and is valid only on bivariate models (Enders 2010), the Johansen Cointegration Test is the appropriate test for multivariate models.

To implement this test, the Dickey-Pantula principle could be applied in determining whether there is indeed cointegration among the variables of the model. This is done by using the most restricted option (Model 2) down to the least restrictive option (Model 4). Once cointegration is detected, further testing is discontinued (Asterious and Hall 2007).

The test statistics are trace statistics and maximum eigenvalue statistics whose formulas are likelihood ratio statistics as follows:

$$
\begin{aligned}
& \lambda_{\text {trace }}=-T \sum_{I=r+1}^{n} \ln \left(1-\lambda_{i}\right) \\
& \lambda_{\max }=-T \ln \left(1-\lambda_{r+1}\right)
\end{aligned}
$$

where $\lambda=$ number of characteristic roots and $T=$ number of observations. If the computed trace and maximum eigenvalue statistics exceed critical values at specified level of significance, the null of no co-integration is rejected. Otherwise, there is no cointegration.

\subsubsection{Test of endogeneity of variables: Hausman specification test}

Inasmuch as the empirical models to be estimated incorporate certain variables which are present in both equations, a problem of simultaneity or endogeneity may occur. If there is endogeneity in some of the explanatory variables of the models this would violate the assumption that the covariance of the explanatory variable and the error term is zero.

To rule out simultaneity or endogeneity, the Hausman Specification test will be applied. The procedure works by first obtaining the reduced forms of the structural equations and estimating them by ordinary least squares (OLS) procedure. The residuals from the reduced form estimates are treated as another explanatory variable in one of the structural equations and the model reestimated by OLS. If the coefficient of the estimated residuals in the equation is statistically significant, there is endogeneity problem. A re-estimation of the entire system of equations using a simultaneous equation approach or by instrumental variables would have to be resorted to Gujarati and Porter (2009). 


\subsection{Presentation and analysis of data}

Japan has been an active trading partner of the Philippines. In 2000 Japan accounted for $14.73 \%$ of Philippine export. Figure 2 shows the historical export trade value of the Philippines to Japan in logarithm form. Although trade value has been increasing, a sharp
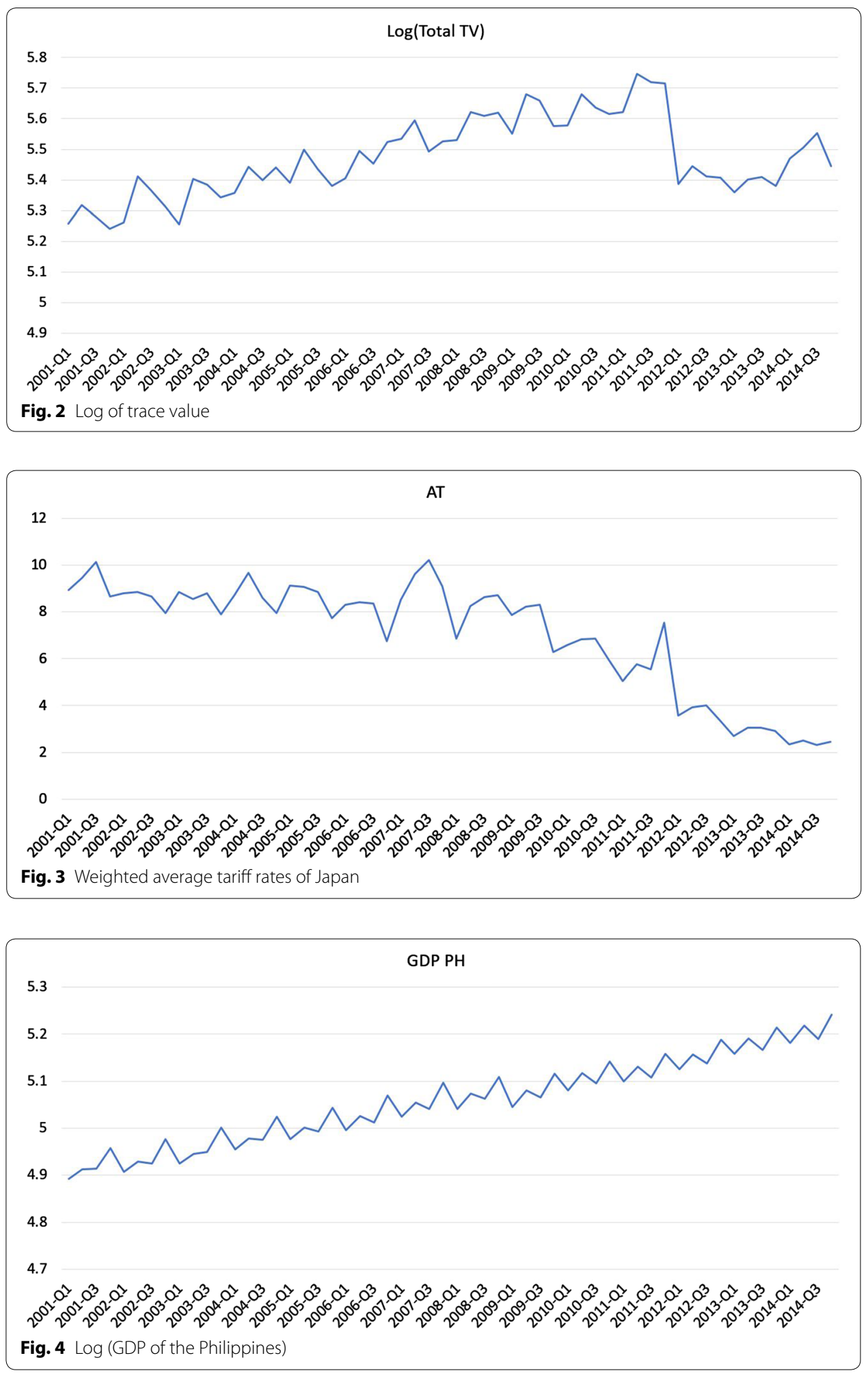


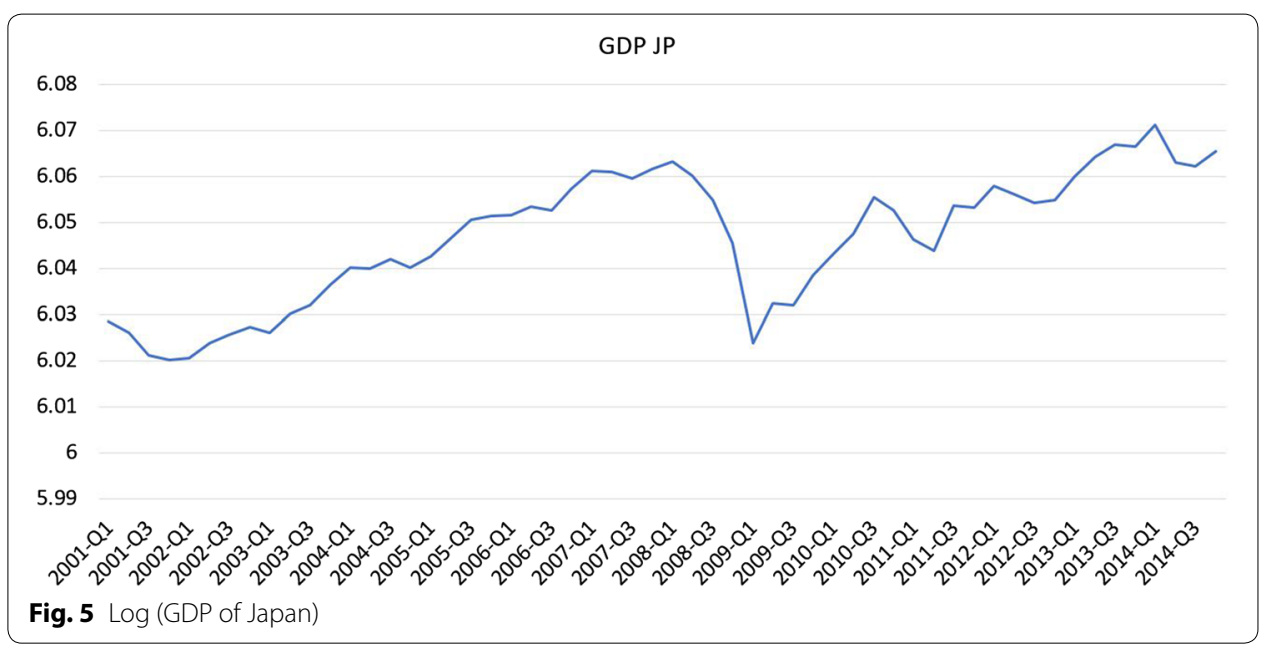

Table 1 Initial regression result

Dependent Variable: LOG(TOTAL_TV)

Method: Least Squares

Sample: 156

Included observations: 56

Variable Coefficient Prob.

\begin{tabular}{|c|c|c|c|c|}
\hline C & -17.65535 & 0.22410 & $R$-squared & 0.71115 \\
\hline LOG(GDP_PH) & 1.085978 & 0.00190 & Adjusted R-squared & 0.68849 \\
\hline LOG(GDP_JP) & 1.179804 & 0.33220 & Prob(F-statistic) & 0.00000 \\
\hline AT & 0.139925 & 0.00000 & Durbin-Watson stat & 0.92256 \\
\hline
\end{tabular}

decline in trade value happened in the first quarter of 2012. This may have been the effect of the ASEAN-Japan Comprehensive Economic Partnership (AJCEP) that increased the trade agreements of Japan to other ASEAN countries. The AJCEP may have affected importation of Japan from the Philippines. Figure 3 is the historical weighted average tariff imposed by Japan to Philippine exports.

Figure 4 and 5 is the historical real GDP of Philippines and Japan. Both countries manifested an increasing real GDP since 2001.

Unit root test was initially utilized in order to test for the stationarity of the variables before any regression procedure is performed. Using the Augmented Dickey-Fuller, all variables are found to be stationary at the second difference.

Table 1 is the initial regression result using log of Trade Value (TV) as dependent variable.

The initial regression result (Table 1 ) has an R-squared of 0.71 , indicating that $71.11 \%$ of the variations in the trade value (TV) is explained by the variations in the GDP of Philippines and Japan, the average tariff rate (AT), and the JPEPA. Although prob. of the AT indicates that it is statistically significant, the relationship of AT to TV is positive instead of negative. Also, low Durbin-Watson stat indicates possibility of serial autocorrelation in the model. 
Table 2 Modified regression result Dependent Variable: LOG(TOTAL_TV)

Method: Least Squares

Sample (adjusted): 256

Included observations: 55 after adjustments

HAC standard errors \& covariance (Bartlett

kernel, Newey-West fixed

bandwidth $=4.0000$ )

Variable Coefficient Prob.

\begin{tabular}{|l|r|r|}
\hline C & -20.78864 & 0.05920 \\
\hline LOG(GDP_PH) & 0.974757 & 0.00000 \\
\hline LOG(GDP_JP) & 1.578356 & 0.08330 \\
\hline AT & 0.046702 & 0.04650 \\
\hline AT(-1) & -0.03625 & 0.03890 \\
\hline DUMMY_FOR_JPEPA & 0.281847 & 0.00020 \\
\hline D2 & -0.662098 & 0.00000 \\
\hline
\end{tabular}

$\begin{array}{lr}\text { R-squared } & 0.85270 \\ \text { Adjusted R-squared } & 0.83429 \\ \text { Prob(F-statistic) } & 0.00000 \\ \text { Prob(Wald F- } & \\ \text { statistic) } & 0.00000 \\ \text { Durbin-Watson stat } & 1.65206 \\ \text { Wald F-statistic } & 88.30351\end{array}$

The model is revised (Table 2) adding a lag variable, AT(-1) to represent the lag effect of lower average tariff to trade value and the introduction of another dummy variable (D2) to represent the implementation of the AJCEP in the first quarter of 2012 which may have affected the exports of the Philippines to Japan. HAC procedure using NeweyWest was used in order to statistically correct for autocorrelation.

The modified regression model has a higher $R$-squared of 0.85270 . AT remains to have a positive and significant effect to trade value, however, the lag of AT shows a negative and significant effect on TV. This means that a decrease in AT will have a one period lag effect to TV. The dummy variable D2 also shows a negative significant effect to TV. This validates that the implementation of AJCEP diverted some of the importation of Japan from the Philippines to other ASEAN countries.

Other diagnostic tests were performed to ensure statistical reliability of the model. The variables are normally distributed based on the Jarque-Bera test for normality. Based on the Ramsey RESET, there is no specification errors. Further, Dickey-Pantula Procedure was performed to test for co-integration, long run relationship between the variables.

\subsection{Summary and conclusions}

Based on the findings, tariff elimination under JPEPA has beneficial effect on trade in terms of increasing Philippine export to Japan. It must be noted as well that the negative relationship between AT and TV has a lag effect. The introduction of another trade agreement creates both trade diversion and creation. In the case of JPEPA and ACJEP, where Philippines and Japan are both partner countries, Japan increased its number of trading partners which resulted to trade diversion from the Philippines to trade creation to other ASEAN countries. 
The model using weighted average tariff rates may also be used by other researchers in assessing gains from trade brought about by other regional trade agreements that involve tariff elimination. It can also be used as a basis for countries to engage into more trade agreements with other countries in order to increase their export potentials.

Since Japan is a major market of Philippine export, the beneficial effect of JPEPA to trade may benefit the Philippines significantly. Future researchers may prove through an empirical paper the benefits of JPEPA to trade value to the overall development of Philippines and Japan.

Based on the findings of the study, bilateral trade agreement is able to expand the export of the Philippines with its trade partner, Japan. Based on the export data of Philippine export to Japan, there are certain commodities that were initially decreasing prior to the agreement that significantly increased, 7 years since the implementation of the agreement such as: meat and edible meat offal (15,3312.2\%), umbrellas, sun umbrellas, walkingsticks, whips, riding-crops and parts thereof (1878.1\%), explosives; pyrotechnic products, matches, pyrophoric alloys, certain combustible preparations (1091.7\%). It is therefore recommended to increase the number of bilateral trade agreement of the Philippines with other countries in order to boost export. It is further recommended to pursue assessment of other trade agreements undertaken by the Philippines to support this conclusion.

\section{Authors' contributions}

AN and VT both contributed to the introduction. AN gathered the journals wrote majority of the Review of Related Literature. VT made substantial contribution in the methodology. AN run the data using appropriate test with the aid of VT. AN and VT both made the conclusions and recommendations.

\section{Author details}

${ }^{1}$ The Graduate School, University of Santo Tomas, Manila, Philippines. ${ }^{2}$ College of Commerce and Business Administration, University of Santo Tomas, Manila, Philippines. ${ }^{3}$ Research Center for Social Sciences and Education, University of Santo Tomas, Manila, Philippines.

\section{Acknowledgements}

Not applicable.

Competing interests

The authors declare that they have no competing interests.

\section{Availability of data and materials}

Data used on this study was generated through Philippine Statistics Authority (PSA) through Trade Statistics for International Business Development. Data on real gross domestic product (GDP) of the Philippines and Japan would be sourced online from the Asian Development Bank (ADB) and the International Monetary Fund (IMF). Data on the specified tariff per type of products traded will be gathered from the Trade Analysis Information System (TRAINS) of the United Nations Conference on Trade and Development (UNCTAD).

\section{Funding}

Not applicable.

\section{Publisher's Note}

Springer Nature remains neutral with regard to jurisdictional claims in published maps and institutional affiliations.

Received: 10 July 2018 Accepted: 12 November 2018

Published online: 21 November 2018

\section{References}

Ali A, Caldentey E (2007) The new bilateral regional free trade agreements in the Americas. Bus Finance Econ Emerg Econ 2(1):205-239

Arvis J, Shepherd B (2013) The Poisson quasi-maximum likelihood estimator: a solution to the 'adding up' problem in gravity models. Appl Econ Lett 20:515-519

Asteriou D, Hall S (2007) Applied Econometrics: A Modern Approach Using Eviews and Microfit Revised Edition. Palgrave Macmillan

Benedictis L, Taglioni D (2011a) The gravity model of international trade. University of Macerata, Macerata 
Benedictis L, Taglioni D (2011b) The gravity model in international trade, chapter 4. In: De Benedictis L, Salvatici L (eds) The trade impact of European Union preferential policies: an analysis through gravity models. Springer, Berlin, pp $55-89$

Bilas V, Franc S (2016) The effects of mega-regional trade agreements on the multilateral trading system. J Econ Mark Commun 12(2): 1-33

Boxell L (2015) K-fold cross-validation and the gravity model of bilateral trade. Atlanta Econ J 43(2):289-300

Bui T (2008) Regional integration and economic growth in the long run: a comparative case study of Vietnam and Mexico in the Asia-Pacific region. J Int Bus Res 7(3):1-26

Bujang A (2016) The Hecksher-Ohlin versus Linder's theory: evidence from Malaysian exports. J Bus Retail Manag Res (JBRMR) 10(2):85-93

Burger M, Oort F, Linders G (2009) On the specification of the gravity model of trade: zeros, excess zeros and zero-inflated estimation. Spat Econ Anal 4(2):167-190

Chen B, Li Y (2014) Analyzing bilateral trade barriers under global trade context: a gravity model adjusted trade intensity index approach. Rev Dev Econ 18(2):326-339

Cipkute E (2016) The gravity model for assessing trade patterns: the case of Baltic states. Ekonomika 95(3):81-97

Clausing K (2001) Trade creation and trade diversion in the Canada-United States free trade agreement. Can J Econ 34(3):677-696

Danao R (2013) Introduction to Statistics and Econometrics. University of the Philippines Press

Drzewoszewska N (2014) Searching for the appropriate measure of multilateral trade-resistance terms in the gravity model of bilateral trade flows. Dyn Econ Model 14:29-49

Egger P, Staub K (2016) GLM estimation of trade gravity models with fixed effects. Empir Econ 50:137-175

Eita J (2016) Estimating export potential for a small open economy using a gravity model approach: evidence from Namibia. J Dev Areas 50(4):273-288

Enders C (2010) Applied Missing Data Analysis. Guilford Press

Fratianni M, Oh C (2009) Size of regional trade agreements and regional trade bias. Appl Econ Lett 16:1603

Freund C (2010) Third-country effects of regional trade agreements. World Econ 33(11):1589-1605

Garcia E, Pabsdorf M, Herrera E (2013) The gravity model analysis: an application on MERCOSUR trade flow. J Econ Policy Reform 16(4):336-348

Gervais A (2015) Trade and growth: a gravity approach. South Econ J 82(2):453-470

Ghosh S (2011) The gravity model in international trade. advances and applications. Rev Int Econ 19(5):979-981

Girma S, Kneller R, Pisu M (2008) Trade creation, replacement, and destruction in regional trade agreements: micro-level evidence for the UK. Rev Int Econ 16(1):142-158

Gomez-Herrera E (2013) Comparing alternative methods to estimate gravity models of bilateral trade. Empir Econ 44:1087-1111

Grant J, Lambert D (2008) Do regional trade agreements increase members'agricultural trade? Am J Agric Econ 90(3):765-782

Gujarati D (2011) Basic econometrics, 4th edn. The McGraw-Hill Companies, New York

Gujarati D, Porter D (2009) Basic econometric. McGraw-Hill Irwin, New York

Hayakawa K, Ito T, Kimura F (2016) Trade creation effects of regional trade agreements: tariff reduction versus non-tariff barrier removal. Rev Dev Econ 20(1):317-326

Hndi B, Maitah M, Mustofa J (2016) Trade impacts of selected free trade agreements on agriculture: the case of selected North African countries. Agris On-line Papers Econ Inform 8:39-50

lqbal J (2016) An analysis of Pakistan's exports using gravity model. Abasyn J Soc Sci 9(1):271

Jalles J (2012) Openness, regional trade agreements and growth: evidence from Asia. Asian Econ J 26(1):63-85

Jarreau J (2015) Determinants of trade policy: insights from a structural gravity model. World Bank Econ Rev 29:155-163

Kahouli B, Maktouf S (2015) Trade creating and diversion effects in the mediterranean area: econometric analysis by gravity model. J Int Trade Econ Dev 24(1):76-104

Khosla R (2015) Intra-regional trade in Africa and the impact of Chinese intervention: a gravity model approach. J Econ Dev 40(4):41-66

Kulkarni K, Gupte R, Sethi S (2015) Gravity model: India's exports. SCMS J Indian Manag 12(4):38-50

Kunroo M, Azad N (2015) Theory-based specification of the gravity equation: an analysis using European Union as an example. J Int Econ 6:101

Liu T (2007) The impact of regional trade agreements on trade. Chin Econ 40(2):70-96

Liu X (2016) Trade agreements and economic growth. South Econ J 82(4):1374-1401

Luqman A, Bakar N, Aziz M (2015) Regionalism and ECOWAS trade performance: a gravity model approach. Bogazici J Rev Soc Econ Adm Stud 29(2):59-71

Madah M, Nagheli S (2016) The analysis of the effect of tax tariffs and trade flows on income gap in gravity model for member countries in OPEC. Int J Manag Account Econ 3(1):45-60

Mohmand Y, Salman A, Mughal K, Imran M, Makarevic N (2015) Export potentials of Pakistan: evidence from the gravity model of trade. Eur J Econ Stud 14(4):212-220

Naanwaab C, Diarrassouba M (2013) The impact of economic freedom on bilateral trade: a cross-country analysis. Int J Bus Manag Econ Res 4(1):668

Nastic V (2013) Application of gravity model for analysis of Bosnia and Herzegovina export. Proc Fac Econ 5(7):123-136

Oncel B, Tekce M (2014) Modelling trade flows between Turkey and former Soviet Union countries: a gravity analysis. Marmara Univ J Econ Adm Sci 36(1):391-408

Papalia R, Bertarelli S (2015) Trade cost in bilateral trade flows: heterogeneity and zeroes in structural gravity models. World Econ 38(11):1744-1762

Park I, Park S (2011) Best practices for regional trade agreements. Rev World Econ 147(2):249-268

Park I, Park S (2016) Trade facilitation provisions in regional trade agreements: discriminatory or non-discriminatory? East Asian Econ Rev 20(4):447-467 
Peci F, Holzner M, Kutllovci E (2010) Determinants of Kosovo trade: a gravity model approach. South East Eur J Econ Bus 2:PP.33-41

Proenca I, Sperlich S, Savasci D (2015) Semi-mixed effects gravity models for bilateral trade. Empir Econ 48:361-387

Quammer N, Baba S (2016) Export performance of Indian walnut: decomposition analysis and gravity model approach. Agric Econ Res Rev 29(2):239-251

Rahman K, Molla R, Murad M (2008a) Japan-Malaysia free trade agreement: expectations and achievements. J Comp Int Manag 11(1):29-42

Rahman K, Molla R, Murad M (2008b) The China factor blunts the cutting-edge of the Japan-Malaysia free trade agreement. Glob Econ J 8(4):1524-5861

Ravishankar G, Stack M (2014) The gravity model and trade efficiency: a stochastic frontier analysis of eastern European countries' potential trade. World Econ 37(5):690-704

Reyes J, Wooster R, Shirrell S (2014) Regional trade agreements and the pattern of trade: a networks approach. World Econ 37(8):1128-1151

Sanora R (2014) All economic freedom is not created equal: evidence from a gravity model. Contemp Econ Policy 32(1):30-41

Sen R, Srivastava S, Pacheco G (2013) The early effects of preferential trade agreements on intra-regional trade within ASEAN + 6 members. J Southeast Asian Econ 30(3):237-249

Sherif S (2013) Intra-regional trade, evidence from the UAE: a gravity model approach. Int J Econ Perspect 7(3):57-65

Silva S, Nelson D (2012) Does aid cause trade? Evidence from an asymmetric gravity model. World Econ 35(5):545-577

Sohn C, Lee H (2010) Trade structure, FTAs, and economic growth. Rev Dev Econ 14(3):683-698

Stack M (2009) Regional integration and trade: controlling for varying degrees of heterogeneity in the gravity model. World Econ 32(5):772-789

Stoneman C, Thompson C (2007) Trading partners or trading deals? The EU and US in Southern Africa. Rev Afr Polit Econ 34(112):227-245

Suvannaphakdy S, Toyoda T (2014) Impact of regional trade agreements in east Asia on members'trade flows. J Southeast Asian Econ 31(3):361-378

Tansey M, Hanson T (2011) The gravity model of trade applied to developing countries. South Bus Econ J 34(3/4):p51

Urata S (2004) The emergence and proliferation of free trade agreements in East Asia. Jpn Econ 32(2):5-52

Urata S, Okabe M (2014) Trade creation and diversion effects of regional trade agreements: a product-level analysis. World Econ 37(2):267-289

Vicard V (2009) On trade creation and regional trade agreements: does depth matter? Rev World Econ 145(2):145-167

Yoshimatsu H (2005) Japan's Keidanren and free trade agreements: societal interest and trade policy. Asian Surv 45(2):258-278

Yoshimatsu H, Ziltener P (2010) Japan's FTA strategy toward highly developed countries: comparing Australia's and Switwerland's experiences. Asian Surv 50(6):1058-1081

Zhang Y, Zhang G, Fung H (2007) The prospects for China's free trade agreements. Chin Econ 40(2):5-35

Zhou M (2015) The efficacy of regional trade agreements, 1958-2006: the effect of institution creation on market expansion. Sociol Forum 30(3):721-742

\section{Submit your manuscript to a SpringerOpen ${ }^{\circ}$ journal and benefit from:}

- Convenient online submission

- Rigorous peer review

- Open access: articles freely available online

- High visibility within the field

- Retaining the copyright to your article

Submit your next manuscript at $\boldsymbol{\nabla}$ springeropen.com 